\title{
Midterm outcomes after primary stenting in treatment of atherosclerotic iliac arteries
}

Mehmet Atay ${ }^{1}$, Onur Saydam², Deniz Serefli ${ }^{2}$, Aysen Yaprak Engin ${ }^{2}$, Burcin Abud ${ }^{2}$, Ayse Gul Kunt ${ }^{2}$ ${ }^{1}$ Department of Cardiovascular Surgery, Bahçelievler State Hospital, Istanbul, Turkey
${ }^{2}$ Department of Cardiovascular Surgery, Tepecik Training and Research Hospital, Izmir,
Turkey

Submitted: 22 January 2021; Accepted: 7 February 2021

Online publication: 21 March 2021

Arch Med Sci 2022

DOI: https://doi.org/10.5114/aoms/133118

Copyright $\odot 2022$ Termedia \& Banach

\section{Abstract}

Introduction: The purpose of this study was to report the midterm outcomes of primary stenting of iliac arteries with additional factors which affect the outcome and to compare the results between patients with simple and complex aortoiliac occlusive disease (AIOD).

Material and methods: The study took place from January 2015 to March 2018 and included 103 lesions in 93 patients with common iliac artery (CIA) and/or external iliac artery (EIA) lesions accompanied with severe claudication or critical limb ischemia. Balloon-expandable stents (BMS), self-expandable stents (SES) and covered stents (CS) were used to treat the lesions. Results: Lesions of 93 patients that were in the CIA and/or EIA and treated with ET were included in the study $(n=103)$. Seventy-one $(68.9 \%)$ lesions were classified in the simple AIOD group (TASC II A-B) while 32 (31.1\%) were classified in the complex AIOD (TASC II C-D) group. In $72.8 \%$ of the lesions only mild calcification was detected while $27.2 \%$ of lesions had moderate or severe calcification. Mean stent diameter for CIA position was $8.26 \pm 0.8 \mathrm{~mm}$ and for EIA position was $7.52 \pm 0.8 \mathrm{~mm}$. Mean lesion length in patients treated with BMS was $52.5 \pm 21.0 \mathrm{~mm}$ while in SES it was $63.6 \pm 28.3(p=0.03)$. Technical success was achieved in 101 (98.1\%) lesions. Significant differences in primary ( $93 \%$ vs. $63 \%$ ) and secondary (98\% vs. $82 \%$ ) patency rates at 24 months were found between patients in simple and complex AIOD groups $(p<0.001, p=0.001)$.

Conclusions: In our study, it was found that the primary stenting in patients who had AIOD had satisfactory results with high immediate success, low complication rates and acceptable midterm outcomes.

Key words: iliac artery, atherosclerosis, endovascular procedures, stents, self-expandable metallic stents.

\section{Introduction}

Aortoiliac occlusive disease (AIOD) constitutes $30 \%$ of PAD and is classified in the Trans-Atlantic Inter Society Consensus II classification (TASC II) $[1,2]$. Although there are some shortcomings in TASC II, the treatment approaches have taken shape based on the severity of the lesions [3]. Open surgery has been the gold standard method; however, revascularization approaches for AIOD are changing with developing technologies and experience, and TASC II recommendations can be reconsidered in some cases. Today one third of the endovascular treatments (ET) for chronic total occlusions (CTO) are applied to the iliac arteries [4, 5]. This

\author{
Corresponding author: \\ Onur Saydam MD \\ Department of \\ Cardiovascular Surgery \\ Tepecik Training and \\ Research Hospital \\ University of Health Sciences \\ İmir Tepecik Research \\ 35000, Izmir, Turkey \\ Tel.: 00902324696969 \\ E-mail: onursaydam@ \\ hotmail.com
}


change has become more evident in the past two decades [6, 7]. Various types of ET approaches are performed for AIOD - plain old balloon angioplasty (POBA), drug-eluting balloon angioplasty (DEB), cutting balloons, bare-metal balloon expandable stents (BMS), self-expandable stents (SES), and covered stents (CS) - which are chosen according to the anatomical features. However, since it has better outcomes, the primary stenting method is one step ahead compared to other methods regardless of the stent type [8].

The ET options of AIOD have evolved from the effectiveness of the primary stenting; however, there is still insufficient evidence on the factors that affect the outcomes of the ET in AIOD lesions $[9,10]$. In this study, we aimed to report the outcomes of primary stenting of AIOD, determine additional factors that affect the outcome and compare the results between patients with simple and complex AIOD.

\section{Material and methods}

\section{Study design}

The study was designed as a retrospective study. Patients treated with primary stenting for AIOD between January 2015 and January 2018 were included. The Clinical Research Ethical Committee of Tepecik Training and Research Hospital approved the study (2018/13-5). Medical data were searched for patient demographics, vascular disease risk factors, as well as procedural and follow-up data. The clinical status of patients was evaluated with the Rutherford classification. The study consisted of 103 lesions in 93 patients with common iliac artery (CIA) and/or external iliac artery (EIA) lesions accompanied with severe claudication (Rutherford category 3 ) or critical limb ischemia (CLI) (Rutherford category 4 or higher) and treated with ET. Individual limbs were counted separately; patients undergoing bilateral procedures were recorded as separate inputs. All procedures and follow-ups were conducted by the cardiovascular surgery department. Patients under 18 years old and patients with previous endovascular treatment other than primary stenting or with previous surgical treatment of the AIOD were excluded. Patients admitted with acute limb ischemia and history of severe renal failure with e-GFR $<30 \mathrm{ml} / \mathrm{min} / 1.73 \mathrm{~m}^{2}$ were also excluded. However, patients who had end stage renal disease were included.

Patients were directed from the outpatient clinic for elective procedures unless they had CLI. Patients with CLI were scheduled for urgent intervention.

Lesions were classified into two groups according to TASC II guidelines. Seventy-one (68.9\%) le- sions were classified as simple AIOD (TASC A-B) while $32(31.1 \%)$ were classified as complex AIOD (TASC C-D).

\section{Procedures and stents}

For preoperative imaging, the first examination was done with Duplex ultrasound (DUS) in all patients. For patients with positive findings in DUS, further imaging was performed with computed tomography angiography (CTA). Calcium score was detected with CTA and defined as none-mild or moderate-severe. All procedures were performed in the interventional angiography laboratory (Siemens AXIOM Artis dTA, Siemens Healthcare, Erlangen, Germany). In case of ipsilateral infra-inguinal PAD accompanying AIOD, two-stage treatment was applied and AIOD was treated in the first step. Procedures were performed percutaneously under local anesthesia and no general anesthesia was utilized for any patient. Access was obtained via the retrograde common femoral artery (CFA) and proximal superficial femoral artery (SFA) or crossover from the contralateral CFA under ultrasound guidance. However, in unsuccessful attempts with these techniques, they were combined with antegrade approach via brachial artery. Depending on stent sizes, 6 Fr or 7 Fr vascular sheaths were inserted; afterward, intra-arterial heparin of $100 \mathrm{IU} / \mathrm{kg}$ dosage was applied. Anticoagulation efficacy was followed up with activated clotting time (ACT). If the ACT value was below 180 seconds, an additional dose of heparin was administered.

The intimal tracking approach was used. A 0.035-inch hydrophilic guidewire (ZIPwire, Boston Scientific, Natick, MA), with the help of support catheters (Navicross, Terumo, Somerset, NJ or Rubicon35, Boston Scientific, Natick, MA) was used to cross the CTO. The diagnostic catheter was advanced proximal to the aortic lesion, and a digital subtraction angiogram was performed via a power injector afterwards. In cases of CTO or near occlusion, predilatation was performed with $4 \mathrm{~mm}$ POBA to facilitate stent delivery. The delivery system was positioned to cover the stenotic or occluded segment. Stent diameter selection was determined by the diameter of the healthy section of the CIA and EIA. A BMS (Visi-Pro, Medtronic, Dublin, Ireland), balloon-expandable CS (Advanta V12, Atrium Medical Inc., Hudson, NH, USA), and SES (Epic Boston Scientific Corp., Natric, MA, USA) were implanted. Stent choice was left to the discretion of the treating physician. Completion angiogram was performed routinely to confirm patency and to rule out extravasation. Technical success was defined as an absence of residual stenosis over $30 \%$ on completion angiography. An Angioseal (Terumo, Somerset, NJ) closure device was used with the discretion of the physician. 


\section{Medical therapy}

Dual anti-platelet therapy that included a $300 \mathrm{mg}$ loading dose of clopidogrel and $100 \mathrm{mg}$ of acetyl salicylic acid (ASA) was commenced immediately after the procedure. Afterward dual antiplatelet therapy was continued at least six months after discharge with a daily clopidogrel dose of $75 \mathrm{mg}$ and an ASA dose of $100 \mathrm{mg}$.

\section{Study end points}

Primary patency was the primary endpoint of our study. Primary patency was defined as uninterrupted patency after the index procedure without reintervention on the treated segment during follow-up. Secondary patency was defined as the patency maintained with a reintervention for the treated segment during follow-up. Procedural success was defined as patency shown in the control angiogram after stent deployment in the index procedure. Restenosis was defined as a more than 30\% diameter reduction on the angiogram of the target lesion with accompanying symptoms of claudication. Stent patency was based on clinical and radiological evaluations. Patients were followed up by aortoiliac DUS at 3, 6, 12, 18, and 24 months after intervention. If significant stenosis was detected with DUS, further imaging was performed with CTA.

\section{Statistical analysis}

Statistical analysis was performed using SPSS Statistics for Mac Version 20 (IBM Corp. Released 2011, Armonk, NY). Variables in numeric configuration were summarized as mean SD values and median (min.-max.) values. Cross table analysis was used to evaluate the categorical variables and shown numerically as percentages. Pearson's correlation test was used to measure the statistical relationship or association between continuous variables. Student's $t$-test was used for normally distributed data and the Mann-Whitney $U$ test was performed for non-normally distributed data. Survival analysis with the Kaplan-Meier log rank test was used to analyze the stent patency. A $p$-value less than 0.05 was considered indicative of a statistically significant difference.

\section{Results}

Lesions of 93 patients that were in the $\mathrm{CIA}$ and/ or EIA and treated with ET were included in the study ( $n=103)$. The majority of the cohort was male $(n=64,68.8 \%)$, and median age was 63 years (range 41-85). Patients' demographic data and risk factors are summarized in Table I.

All patients were symptomatic, and all lesions were classified according to TASC II criteria. Seventy-one $(68.9 \%)$ lesions were classified in the simple AIOD group (TASC II A-B) while 32 (31.1\%) were classified in the complex AIOD (TASC II C-D) group. Preprocedural and periprocedural details are summarized in Table II.

Eighty-four percent of the lesions caused severe claudication (Rutherford 3) and $15.5 \%$ had CLI (Rutherford 4, 6.8\%, Rutherford 5 4.9\%, Rutherford $63.9 \%$ ) on admission. Compared to the simple AIOD group, CLI was seen more frequently in the complex AIOD group ( $p<0.001)$.

In $72.8 \%$ of the lesions only mild calcification was detected while $27.2 \%$ of lesions had moderate or severe calcification. In 54 (52.4\%) lesions, the disease was located only in the CIA while in $22(21.4 \%)$ lesions, the disease was located only in the EIA. Twenty-seven lesions (26.2\%) were located in both the CIA and EIA. Among the complex AIOD group, nearly half of the lesions $(n=14$, 43.8\%) involved both the CIA and EIA.

Ipsilateral severe stenosis or occlusion of the internal iliac artery (IIA) accompanied 41 (39.8\%) lesions, which were more frequently located in the CIA with or without EIA extension $(p<0.001)$.

Additional ipsilateral infra-inguinal PAD accompanied 27 (26.2\%) lesions.

The retrograde CFA or proximal SFA approach was enough in 64 (62.1\%) lesions. However, in 39 (30.1\%) lesions, additional access (crossover from contralateral SFA, $n=31,30.1 \%$; antegrade from brachial artery, $n=8,7.8 \%$ ) was necessary for revascularization.

Table I. Preoperative demographic characteristics of patients

\begin{tabular}{|lc|}
\hline Parameter & $n(\%)$ \\
\hline Patients $(n=93):$ & $64(68.8)$ \\
\hline Male & $63(41-85)$ \\
\hline Age [years] & $76(73)$ \\
\hline Smoker & $85(82.5)$ \\
\hline Hypertension & $76(73.8)$ \\
\hline COPD & $36(35)$ \\
\hline CAD & $53(54.4)$ \\
\hline Diabetes mellitus & $65(63.1)$ \\
\hline Lesion $(n=103):$ & $87(84.5)$ \\
\hline Rutherford classification: & $7(6.8)$ \\
\hline \begin{tabular}{l} 
Hemia \\
\hline 4
\end{tabular} & $5(4.9)$ \\
\hline \begin{tabular}{l} 
Simple (TASC II A-B) \\
\hline 6
\end{tabular} & $41(3.9)$ \\
\hline Complex (TASC II C-D) & $32(27.2)$ \\
\hline
\end{tabular}

CAD - coronary arterial disease, TASC II - transatlantic intersociety consensus, COPD - chronic obstructive pulmonary disease 
Overall median lesion length was $50 \mathrm{~mm}(17-$ $118 \mathrm{~mm})$.

Predilatation with plain old balloon angioplasty (POBA) was performed in 25 (24.3\%) lesions. Predilatation for stent delivery was needed nearly 5 times more in the complex AIOD group $(p<0.001)$.

For CIA lesions BMS and for EIA lesions SES were preferred more frequently. The details of the lesions and stents that were used are given in Table II.

Immediate technical success was achieved in 101 (98.1\%) lesions. Surgical treatment was planned in $2(2.2 \%)$ patients where CTO could not be exceeded. Both patients had calcified and complex AIOD lesions with a mean lesion length of $111 \pm 1.41 \mathrm{~mm}$. The mean procedural duration was $47.2 \pm 18.7 \mathrm{~min}$. Procedural duration was $43.0 \pm 14.8 \mathrm{~min}$ for simple AIOD lesions and $58.5 \pm 23.4$ for complex AIOD lesions ( $p<0.001$ ).

Peri-procedural complications occurred during the treatment of 8 (7.8\%) lesions. Dissection requiring additional stent implantation was observed in $5(4.8 \%)$ lesions. All lesions were treated

Table II. Procedural data of patients

\begin{tabular}{|c|c|}
\hline Parameter & $n(\%),(\min .-\max )$. \\
\hline \multicolumn{2}{|l|}{ Access site $(n=103)$ : } \\
\hline Femoral retrograde & $64(62.1)$ \\
\hline Additional accesses & $39(30.1)$ \\
\hline $\begin{array}{l}\text { Contralateral femoral } \\
\text { retrograde, crossover }\end{array}$ & $31(30.1)$ \\
\hline Brachial, antegrade & $8(7.8)$ \\
\hline \multicolumn{2}{|l|}{ Target lesion $(n=103)$ : } \\
\hline $\mathrm{CIA}$ & $54(52.4)$ \\
\hline EIA & $22(21.4)$ \\
\hline $\mathrm{CIA}+\mathrm{EIA}$ & $27(26.2)$ \\
\hline Lesion length [mm]: & $50(17-118)$ \\
\hline $\mathrm{CIA}$ & $49(17-62)$ \\
\hline EIA & $42(25-58)$ \\
\hline $\mathrm{CIA}+\mathrm{EIA}$ & $82(30-118)$ \\
\hline \multicolumn{2}{|l|}{ Stent types: } \\
\hline \multicolumn{2}{|l|}{$\mathrm{CIA}$} \\
\hline BMS & $72(69.9)$ \\
\hline CS & $9(8.7)$ \\
\hline \multicolumn{2}{|l|}{ EIA: } \\
\hline SES & $42(40.8)$ \\
\hline BMS & $5(4.9)$ \\
\hline CS & $2(1.9)$ \\
\hline \multicolumn{2}{|c|}{ Mean stent diameter $[\mathrm{mm}]$ : } \\
\hline $\mathrm{CIA}$ & $8.28 \pm 0.8$ \\
\hline EIA & $7.52 \pm 0.8$ \\
\hline
\end{tabular}

metal stent, CS - cover stent, SES - self-expandable stent successfully with an additional stent implantation (BMS $n=2$, SES $n=3$ ). Distal embolization occurred during the treatment of 2 lesions and was treated with catheter directed thrombolysis. One EIA rupture was observed $(0.97 \%)$ and treated with CS. In one patient the distal tip of the SES delivery system was separated from the system during crossing of the severe stenosis in the EIA; the $7 \mathrm{Fr}$ vascular sheath was replaced with a $10 \mathrm{~F}$ vascular sheath and an attempt was made to catch the tip with a snare catheter. After unsuccessful attempts cut-down was performed via a small incision and the tip was removed with a Fogarty embolectomy catheter. Afterward, successful endovascular recanalization with an SES was performed. Periprocedural complication was observed more commonly in the complex AIOD group and in lesions with moderate or severe calcification ( $p=0.017, p=0.001$ ) (Table III).

Median follow-up was 26 months (2-72). The overall primary patency rates at 12 and 24 months after ET were $95 \%$ and $85.1 \%$ respectively, while the secondary patency rates at 12 and 24 months were $95.9 \%$ and $94.1 \%$ respectively.

Significant differences in primary (93\% vs. $63 \%)(p<0.001)$ and secondary $(98 \%$ vs. $82 \%)$ $(p=0.001)$ patency rates at 24 months were found between patients in simple and complex AIOD groups.

Subgroup analysis showed significant differences in primary and secondary patency at 24 months for different arterial segments. CIA + EIA lesions had significantly lower primary and secondary patency rates at 24 months compared with isolated $\mathrm{CIA}$ and EIA lesions (67\% vs. $94 \%$ and $84 \%$, log rank: $12.2, p=0.002$ for PP at 24 months and $82 \%$ vs. $100 \%$ and $94 \%$, log rank: $11.2, p=0.004$ for SP at 24 months).

Table III. Peri- and post-procedural complications and procedural duration of patients, $p<0.001$

\begin{tabular}{|lc|}
\hline $\begin{array}{l}\text { Complication } \\
\text { or duration }\end{array}$ & $n(\%)$ \\
\hline $\begin{array}{l}\text { Peri-procedural } \\
\text { complication: }\end{array}$ & $8(7.8)$ \\
\hline $\begin{array}{l}\text { Dissection } \\
\text { Rupture }\end{array}$ & $5(4.8)$ \\
\hline $\begin{array}{l}\text { Distal embolization } \\
\text { Post-procedural } \\
\text { complication: }\end{array}$ & $2(0.97)$ \\
\hline $\begin{array}{l}\text { Pseudoaneurysm } \\
\text { Hematoma }\end{array}$ & $6(5.9)$ \\
\hline $\begin{array}{l}\text { Mean procedural duration } \\
\text { (min): }\end{array}$ & $2(1.96)$ \\
\hline $\begin{array}{l}\text { Simple group } \\
\text { Complex group }\end{array}$ & $4(3.93)$ \\
\hline
\end{tabular}


Lesions with severe stenosis or occlusion of IIA had inferior primary and secondary patency at 24 months when compared with lesions that had no or non-significant stenosis in IIA (PP at 24 months $70 \%$ vs. $93 \%, p=0.001$, SP at 24 months $87 \%$ vs. $98 \%, p=0.02$ ). Subgroup analysis in patients with severe stenosis or occlusion of IIA also revealed that these differences in primary patency at 24 months were more significant in $\mathrm{CIA}$ and $\mathrm{CIA}+\mathrm{EIA}$ lesions compared with EIA only $(85 \%$ and $53 \%$ vs. $100 \%, p=0.04)$. However, we did not observe these significant differences in secondary patency $(p=0.70)$.

Lesions combined with ipsilateral infra-inguinal PAD also have significantly lower primary and secondary patency rates at 24 months when compared with healthy infra-inguinal peripheral arteries $(66 \%$ vs. $93 \%, p<0.001$ for PP at 24 months, $83 \%$ vs. $98 \%, p=0.002$ for SP at 24 months). Primary and secondary patency rates are shown in Table IV.

During follow-up, significant in-stent restenosis or occlusion was observed in 13 (6.9\%) lesion. Reintervention in the complex AIOD group was more frequent $(p<0.001)$.

Eleven lesions (10.7\%) which needed reintervention were treated percutaneously either with POBA $(7.8 \%, n=8)$ or BMS $(2.9 \%, n=3)$. Due to unsuccessful reintervention, $2(2.1 \%)$ patients were scheduled for surgery. Patients who had lesion length more than $81 \mathrm{~mm}$ tended to undergo reintervention $(p=0.002)$.

Postprocedural complication was observed in $6(6.5 \%)$ patients. In 2 patients pseudoaneurysm and in 4 patients significant groin hematoma was detected. In both patients with pseudoaneurysm successful ultrasound-guided compression therapy was performed. The groin hematomas did not have pseudoaneurysm formation and were managed conservatively.

Median duration of hospital stay was 1 day (1-13), and subgroup analysis revealed no significant differences between AIOD groups $(p=0.22$ ). Median total cost for interventions was 1125 dollars (875-2950). In one patient with CLI on initial admission, unplanned amputation was performed (1.1\%). No procedural or early mortality was detected during follow-up. Overall mortality was $3 \%$ (Figure 1).

\section{Discussion}

In this study, we investigated our mid-term results of AIOD, and compared outcomes of 103 lesions according to their differences in TASC categories and procedural properties and strongly focused on lesion characteristics which may affect the patency. Immediate technical success was achieved in $98.1 \%$. Overall primary and secondary patency rates at 24 months were $85.1 \%$ and $94.1 \%$, respectively, which demonstrate comparable results to open surgery $[11,12]$.

TASC classification was revised in 2007 to give more consistent recommendations for treatment approaches of AIOD, but there are still some gaps $[3,13,14]$. Endovascular treatments is mostly recommended for TASC A and B lesions while surgical treatment was recommended for patients who had complex lesions classified as TASC C and $D$ lesions. The surgical treatment of AIOD provides good long-term outcomes, but perioperative morbidity has been far from negligible [15]. Therefore, ET in complex lesions gained attention with developing technologies and with the growing experiences, and recent results started to go in favor of ET $[16,17]$. In addition, regardless of

Table IV. Primary and secondary patency at the 24 month

\begin{tabular}{|lcc|}
\hline Parameter (\%) & Primary patency & Secondary patency \\
\hline Overall & 85.1 & 94.1 \\
\hline Simple Group & 93 & 98 \\
\hline Complex Group & 63 & 82 \\
\hline P-value & $<0.001$ & 0.001 \\
\hline EIA & 84 & 94 \\
\hline CIA & 94 & 100 \\
\hline CIA+EIA & 67 & 82 \\
\hline$P$-value & 0.002 & 0.004 \\
\hline IIA occlusion or stenosis - & 93 & 98 \\
\hline IIA occlusion or stenosis + & 70 & 87 \\
\hline P-value & 0.001 & 0.02 \\
\hline Concomitant infrainguinal PAD - & 93 & 98 \\
\hline Concomitant infrainguinal PAD + & 66 & 83 \\
\hline P-value & $<0.001$ & 0.002 \\
\hline CIA -common iliac artery,EIA - & \\
\hline
\end{tabular}

CIA - common iliac artery, EIA - external iliac artery, IIA - internal iliac artery, PAD - peripheral artery disease 

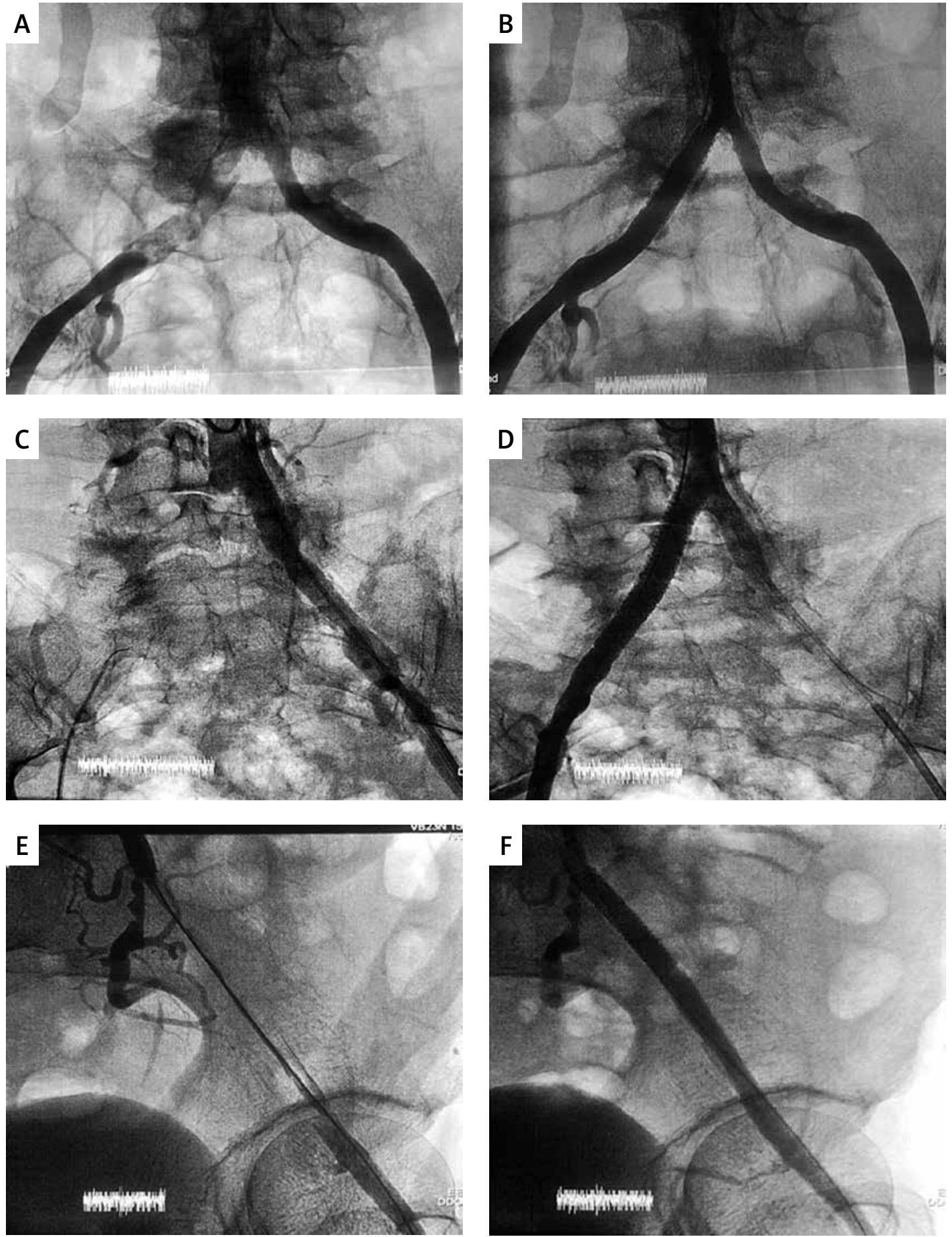

Figure 1. A - Retrograde angiography of right common iliac artery (CIA) showing chronic total chronic occlusion of highly calcified common iliac artery, using a right femoral artery approach. B - Final angiogram; lesion was treated with balloon expandable stent. C - Chronic total occlusion of common and proximal external iliac arteries. D - Final angiography; lesion was treated with 2 balloon expandable stents. E - Chronic total occlusion of highly calcified common iliac artery. $\mathbf{F}$ - Final angiography; lesion was treated with self-expandable stent

the success, duly performed procedures will not adversely affect the success of the subsequent surgical interventions. Therefore, similar to most centers, the ET approach has become the first-line treatment option for almost all AIOD [18]. In parallel, our study revealed that ET can be performed safely and with a high level of technical success. Although there are studies showing better technical success rates in complex lesions compared with simple AIOD, complex AIOD lesions are usually expected to be more challenging compared with simple ones [17, 19, 20]. Accordingly, in our 
study, the complex AIOD group had a lower level of technical success, which is similar to many previous studies [21-23]. The most common reason for technical failure was inability to cross the CTO segment, including inability to break the proximal or distal cap of the occlusion and reentry. Proximal access combined with retrograde access has been emphasized in several studies as a solution [21, 24]. Similarly, in the current study, when the ipsilateral retrograde approach was not successful, combined alternative approaches and CTO catheters were used to resolve the problem. Nevertheless, surgery has been successfully performed in all of our patients whose ET failed.

The overall primary and secondary patency of the CTO lesions reached $85.1 \%$ and $94.1 \%$, respectively. Subgroup analysis showed significant differences in primary and secondary patency between simple and complex AIOD groups. Outcomes are in accordance with many studies concluding that complex TASC lesions have lower patency rates [21, 25-27]. In contrast, there are also studies showing similar results for different TASC categories $[20,28]$. We think that these differences in studies may be associated with the limitations of TASC classification in assessing lesion severity. It is emphasized that lesion severity and extension are more prominent than in the TASC classification. In our study CTO or mixed type lesions were more commonly seen in the complex TASC group and it seems that the combination of lesion length with CTO in the complex TASC group tends to sustain the patency in the midterm.

Compared with the CIA, the EIA has lower patency rates in ET due to smaller diameter and more exposure to stress during movement. In our study, EIA lesions were more common in the complex AIOD group, which may also have affected our outcomes [29]. However, there are also studies showing no differences in patency between CIA and EIA [30, 31].

Another factor which affects our midterm patency rates may be the severe stenosis or occlusion of IIA. In our study, we observed lower primary and secondary patency rates at 24 months in patients with IIA involvement. Subgroup analysis in patients with IIA involvement revealed that this difference was more evident in interventions including the $\mathrm{CIA}$ and $\mathrm{CIA}+\mathrm{EIA}$. The patency of the intervention can be affected by the condition of the target outflow vessel, which has generally been regarded as a poor prognostic factor if outflow vessels are affected. An increase in the number of affected vessels may worsen the patency. Therefore it is not surprising as CIA + EIA lesions with affected IIA had worse patency when both major outflow vessels of the CIA were affected [32]. In parallel with our study, success rate in the midterm can also be negatively affected by the presence of concomitant infra-inguinal lesions [8].

Another controversial issue is which treatment approach should be applied, primary stenting or selective stenting. All patients in our cohort were treated with primary stenting, and this approach is supported by recent studies [26, 33]. Although the DUTCH trial showed that selective iliac artery stenting was as effective as primary stenting, complex AIOD patients were mostly excluded from this trial [34]. Therefore, primary stenting is not only regarded as more advantageous in patency rates, but also in periprocedural complications including distal embolization and dissection when compared with balloon angioplasty alone $[3,8]$.

Morphology of the vessel and the location of the lesion are crucial for selecting the stent type. The BMS is superior in calcified lesion. Because of its greater radial force, recoil incidence can be lowered with BMS. Although radial force helped to reduce recoil incidence in calcified lesions, in non-calcified lesions radial force may cause an increase in the circumferential stress, which may lead to neointimal hyperplasia [35].

The EIA has a more tortuous course than the CIA, where SES can be more advantageous because of their high capability of flexibility. Therefore, in our daily routine, BMS were mostly used in the CIA and highly calcified short EIA lesions, and SES were mostly used in the EIA. CS were reserved for aneurysms, and iatrogenic complications due to their costs and low availability. Compared with BMS, mean stent diameter in SES was smaller and the mean length of lesions in which they were used was longer. Therefore, it is not surprising to find out that the BMS stents had better primary and secondary patency rates at 24 months. These results can be misleading because homogeneous groups could not be created. Here, we think that the effect of lesion characteristics on patency will be more significant than the stent type.

There are studies indicating that stent deployment without predilatation will reduce the incidence of distal emboli [36]. In our study, predilatation was performed only to facilitate the stent delivery in patients with CTO or near occlusion. The diameter of the balloon which is used during predilatation was far below the native vessel diameter and no periprocedural complication was observed due to predilatation. However, in our cohort, in a patient with severe stenosis treated without predilatation, the distal tip of the SES delivery system was separated from the system during crossing the severe stenosis in the EIA.

Our postprocedural complication rate was 5.9\% (6 patients). Pseudoaneurysm emerged in two patients and it was treated with ultrasound guided compression, which has been shown to be an ef- 
fective first-line treatment method in this issue and has been used for many years [37]. Also, four patients who had an inguinal hematoma were treated with a conservative approach and there was no need for surgery in any patient.

In-stent restenosis is the most important factor that affects mid and long-term patency for clinical success in patients with AIOD during the follow-up. In our study, in-stent restenosis was significantly higher in the complex AIOD group. Many factors have been identified for the cause of instent restenosis, including residual stenosis, stent fracture and stress, multiple stenting, long length of stent and lesion, diabetes and neoplasms [3840]. Diabetes and its complications are important therapeutic problems in patients with vascular disease [41]. In the current study most of our patients had diabetes, and therefore high rates of restenosis can be expected in such a cohort. Although in our cohort the rate of reintervention due to restenosis or occlusion is high compared to the results of surgery, the reintervention in ET will be much easier, faster and more comfortable for the patient [42].

There are several limitations to our study, including non-randomization, retrospective design, single-center cohort, and short follow-up.

In our study, it was found that the primary stenting in patients who had AIOD had satisfactory outcomes with high immediate success, low complication rates and comparable midterm outcomes with surgery. Nonetheless, to confirm these favorable results, multicenter, randomized, controlled studies with larger sample size are needed.

\section{Acnowledgments}

Both authors contributed equally to this manuscript: Mehmet Atay, Onur Saydam.

\section{Conflict of interest}

The authors declare no conflict of interest.

\section{References}

1. Selvin E, Erlinger TP. Prevalence of and risk factors for peripheral arterial disease in the United States: results from the National Health and Nutrition Examination Survey, 1999-2000. Circulation 2004; 110: 738-43.

2. DeBakey ME, Lawrie GM, Glaeser DH. Patterns of atherosclerosis and their surgical significance. Ann Surg 1985; 201: 115-31.

3. Norgren L, Hiatt WR, Dormandy JA, et al. Inter-society consensus for the management of peripheral arterial disease (TASC II). Eur J Vasc Endovasc Surg 2007; 33 Suppl 1: S1-S75.

4. Rogers JH, Laird JR. Overview of new technologies for lower extremity revascularization. Circulation 2007; 116: 2072-85

5. Bjorck M, Troeng T, Bergqvist D. Risk factors for intestinal ischaemia after aortoiliac surgery: a combined cohort and case-control study of 2824 operations. Eur J Vasc Endovasc Surg 1997; 13: 531-9.

6. Guez D, Hansberry DR, Gonsalves CF, et al. Recent trends in endovascular and surgical treatment of peripheral arterial disease in the medicare population. AJR Am J Roentgenol 2020; 214: 962-6.

7. Premaratne S, Newman J, Hobbs S, Garnham A, Wall M. Meta-analysis of direct surgical versus endovascular revascularization for aortoiliac occlusive disease. J Vasc Surg 2020; 72: 726-37.

8. Bosch JL, Hunink MG. Meta-analysis of the results of percutaneous transluminal angioplasty and stent placement for aortoiliac occlusive disease. Radiology 1997; 204: 87-96

9. Bekken JA, Vos JA, Aarts RA, de Vries JP, Fioole B. DISCOVER: Dutch Iliac Stent trial: COVERed balloon-expandable versus uncovered balloon-expandable stents in the common iliac artery: study protocol for a randomized controlled trial. Trials 2012; 13: 215.

10. Mwipatayi BP, Sharma S, Daneshmand A, et al. Durability of the balloon-expandable covered versus bare-metal stents in the Covered versus Balloon Expandable Stent Trial (COBEST) for the treatment of aortoiliac occlusive disease. J Vasc Surg 2016; 64: 83-94.e1.

11. Piotrowski JJ, Pearce WH, Jones DN, et al. Aortobifemoral bypass: the operation of choice for unilateral iliac occlusion? J Vasc Surg 1988; 8: 211-8.

12. Schneider JR, Zwolak RM, Walsh DB, McDaniel MD, Cronenwett JL. Lack of diameter effect on short-term patency of size-matched dacron aortobifemoral grafts. J Vasc Surg 1991; 13: 785-90; discussion: 90-1.

13. Hynes N, Akhtar Y, Manning B, et al. Subintimal angioplasty as a primary modality in the management of critical limb ischemia: comparison to bypass grafting for aortoiliac and femoropopliteal occlusive disease. J Endovasc Ther 2004; 11: 460-71.

14. Timaran CH, Prault TL, Stevens SL, Freeman MB, Goldman $\mathrm{MH}$. Iliac artery stenting versus surgical reconstruction for TASC (TransAtlantic Inter-Society Consensus) type B and type C iliac lesions. J Vasc Surg 2003; 38: 272-8.

15. Chiu KW, Davies RS, Nightingale PG, Bradbury AW, Adam DJ. Review of direct anatomical open surgical management of atherosclerotic aorto-iliac occlusive disease. Eur J Vasc Endovasc Surg 2010; 39: 460-71.

16. Sutzko DC, Andraska EA, Obi AT, Henke PK, Osborne NH. Risk factors associated with perioperative myocardial infarction in major open vascular surgery. Ann Vasc Surg 2018; 47: 24-30.

17. Chen BL, Holt HR, Day JD, Stout CL, Stokes GK, Panneton JM. Subintimal angioplasty of chronic total occlusion in iliac arteries: a safe and durable option. J Vasc Surg 2011; 53: 367-73.

18. Hulley SB, Cummings SR, Browner WS, Grady D, Newman TB. Designing clinical research: an epidemiologic approach. 4th ed. Lippincott Williams \& Wilkins, Philadelphia 2013; Appendix 6E: 81.

19. Papakostas JC, Chatzigakis PK, Peroulis M, et al. Endovascular Treatment of chronic total occlusions of the iliac arteries: early and midterm results. Ann Vasc Surg 2015; 29: 1508-15.

20. Dattilo PB, Tsai TT, Garcia JA, Allshouse A, Casserly IP. Clinical outcomes with contemporary endovascular therapy of iliac artery occlusive disease. Catheterization and cardiovascular interventions. Catheter Cardiovasc Interv 2012; 80: 644-54.

21. Tsujimura T, lida O, Fujita M, et al. Two-year clinical outcomes post implantation of $\mathrm{Epic}^{\mathrm{TM}}$ self-expanding niti- 
nol stents for the aortoiliac occlusive disease in patients with peripheral arterial disease. J Atheroscler Thromb 2018; 25: 344-9.

22. Bracale UM, Giribono AM, Spinelli D, et al. Long-term results of endovascular treatment of TASC $C$ and D aortoiliac occlusive disease with expanded polytetrafluoroethylene stent graft. Ann Vasc Surg 2019; 56: 254-60.

23. Muller AM, Langwieser N, Bradaric C, et al. Endovascular treatment for steno-occlusive iliac artery disease: safety and long-term outcome. Angiology 2018; 69: 308-15.

24. Meertens MM, Ng E, Loh SEK, Samuel M, Mees BME, Choong A. Transradial approach for aortoiliac and femoropopliteal interventions: a systematic review and meta-analysis. J Endovasc Ther 2018; 25: 599-607.

25. Balzer JO, Gastinger V, Ritter R, et al. Percutaneous interventional reconstruction of the iliac arteries: primary and long-term success rate in selected TASC $C$ and D lesions. Eur Radiol 2006; 16: 124-31.

26. Ichihashi S, Higashiura W, Itoh H, Sakaguchi S, Nishimine K, Kichikawa K. Long-term outcomes for systematic primary stent placement in complex iliac artery occlusive disease classified according to Trans-Atlantic Inter-Society Consensus (TASC)-II. J Vasc Surg 2011; 53: 992-9.

27. Yiğit G, Sarıcaoğlu MC, Çetinkaya F, Özen A, İşcan HZ. Endovascular treatment of chronic total occlusion of iliac/femoral arteries: mid-term follow-up. Turk J Vasc Surg 2020; 29: 7-12.

28. Leville CD, Kashyap VS, Clair DG, et al. Endovascular management of iliac artery occlusions: extending treatment to TransAtlantic Inter-Society Consensus class C and D patients. J Vasc Surg 2006; 43: 32-9.

29. Powell RJ, Fillinger M, Bettmann M, et al. The durability of endovascular treatment of multisegment iliac occlusive disease. J Vasc Surg 2000; 31: 1178-84.

30. Ballard JL, Bergan JJ, Singh P, Yonemoto H, Killeen JD. Aortoiliac stent deployment versus surgical reconstruction: analysis of outcome and cost. J Vasc Surg 1998; 28: 94-101; discussion: 101-3.

31. Lee ES, Steenson CC, Trimble KE, Caldwell MP, Kuskowski MA, Santilli SM. Comparing patency rates between external iliac and common iliac artery stents. J Vasc Surg 2000; 31: 889-94.

32. Ballotta E, Renon L, Toffano M, Piccoli A, Da Giau G. Patency and limb salvage rates after distal revascularization to unclampable calcified outflow arteries. J Vasc Surg 2004; 39: 539-46.

33. Kudo T, Chandra FA, Ahn SS. Long-term outcomes and predictors of iliac angioplasty with selective stenting. J Vasc Surg 2005; 42: 466-75.

34. Klein WM, van der Graaf $Y$, Seegers J, et al. Dutch iliac stent trial: long-term results in patients randomized for primary or selective stent placement. Radiology 2006; 238: 734-44.

35. Timmins LH, Miller MW, Clubb FJ, Jr., Moore JE, Jr. Increased artery wall stress post-stenting leads to greater intimal thickening. Lab Invest 2011; 91: 955-67.

36. Goode SD, Cleveland TJ, Gaines PA; STAG trial collaborators. Randomized clinical trial of stents versus angioplasty for the treatment of iliac artery occlusions (STAG trial). Br J Surg 2013; 100: 1148-53.

37. AbuRahma AF, Hayes JD, Flaherty SK, Peery W. Primary iliac stenting versus transluminal angioplasty with selective stenting. J Vasc Surg 2007; 46: 965-70.

38. Roller RE, Schnedl WJ, Korninger C. Predicting the risk of restenosis after angioplasty in patients with peripheral arterial disease. Clin Lab 2001; 47: 555-9.
39. Higashiura W, Sakaguchi S, Morimoto K, Kichikawa K. Stent fracture and reocclusion after placement of a single self-expanding stent in the common iliac artery and endovascular treatment. Cardiovasc Intervent Radiol 2008; 31: 1013-7.

40. Cosottini M, Michelassi MC, Bencivelli W, et al. In stent restenosis predictors after carotid artery stenting. Stroke Res Treat 2010; 2010: 864724.

41. Tryniszewski W, Gadzicki M, Maziarz Z, et al. Progression of diabetic retinopathy correlated with muscle perfusion disturbances of the lower limbs, with clinically important diagnostic recommendations. Arch Med Sci 2010; 6: 904-11.

42. Schurmann K, Mahnken A, Meyer J, et al. Long-term results 10 years after iliac arterial stent placement. Radiology 2002; 224: 731-8. 